\title{
Prediction of Hospitalization Stay in COPD Exacerbations: The AECOPD-F Score
}

\author{
Filia Diamantea MD, Konstantinos Kostikas MD, Konstantinos Bartziokas MD, \\ Foteini Karakontaki MD, Stamatoula Tsikrika MD, Sofia Pouriki MD, \\ Vlassis Polychronopoulos MD, Napoleon Karagiannidis MD, \\ Aikaterini Haniotou MD, and Andriana I Papaioannou MD
}

\begin{abstract}
BACKGROUND: Hospital admissions for COPD exacerbations account for $70 \%$ of total costs of COPD treatment, and the duration of hospital stay is directly related to this cost. The aim of this study was to investigate possible associations of demographic, clinical, laboratory, and functional parameters with stay of subjects admitted for COPD exacerbations and to provide a score for the prediction of the need for prolonged hospitalization. METHODS: We included 164 consecutive subjects admitted to 2 respiratory medicine departments of 2 tertiary hospitals for a COPD exacerbation, and we evaluated laboratory, clinical, and functional parameters possibly related to the duration of hospital stay. RESULTS: Seven parameters evaluated on subject admission (Antonisen type of exacerbation, number of Exacerbations in the previous year, Charlson index of comorbidities, Oxygenation, Partial pressure of $\mathrm{P}_{\mathrm{aCO}}$ in arterial blood gases, Dyspnea according to the Borg dyspnea scale, and history of chronic respiratory Failure) were able to predict stay and were included in a simple score named AECOPD-F. The area under the curve of the score for the prediction of prolonged hospital stay is 0.960 , and a cutoff point $\geq 3$ predicts prolonged stay with a sensitivity of $84.5 \%$ and a specificity of $92.5 \%$ (95\% CI 0.917-0.984). The AECOPD-F score was validated in a second group of 88 subjects admitted to the hospital for a COPD exacerbation. In the validation group, subjects with a score $\geq 3$ required prolonged stay compared with those with a score $<3(8.0[6.0-10.0]$ vs $6.5[4.0-9.0]$ d, respectively, $P=.007)$. CONCLUSION: The AECOPD-F score could accurately predict stay in hospitalized COPD subjects. The implementation of this score in clinical practice could be useful in the discharge planning of such subjects. Key words: COPD exacerbation; duration of hospital stay; predictors of outcomes; dyspnea; comorbidities. [Respir Care 2014;59(11):1679-1686. () 2014 Daedalus Enterprises]
\end{abstract}

\section{Introduction}

COPD is a leading cause of morbidity and mortality worldwide and results in an economic and social burden

\footnotetext{
Drs Diamantea, Karakontaki, Tsikrika, Pouriki, Polychronopoulos, Karagiannidis, and Papaioannou are affiliated with the Third Respiratory Medicine Department, Sismanogleio General Hospital, Athens, Greece. Dr Kostikas is affiliated with the Second Respiratory Medicine Department, University of Athens Medical School, Athens, Greece. Drs Bartziokas and Haniotou are affiliated with the Respiratory Medicine Department, Amalia Fleming General Hospital, Athens, Greece.
}

This research was supported by the Hellenic Thoracic Society. The authors have reported no conflicts of interest. that is both substantial and increasing. ${ }^{1}$ COPD is one of the most common causes of acute hospital admission. ${ }^{2} \mathrm{~A}$ significant proportion of the cost of managing COPD is attributed to hospital admission due to exacerbations. ${ }^{3}$ It has been estimated that hospital episodes account for $70 \%$ of the total costs of COPD treatment. ${ }^{4}$ The cost of hospitalization is also significantly influenced by the duration of

\footnotetext{
Correspondence: Filia Diamantea MD, Third Respiratory Medicine Department, Sismanogleio General Hospital, Sismanogleiou 1, 15126 Marousi Athens, Greece. E-mail: fdiamantea2001@yahoo.co.uk.
}

DOI: $10.4187 /$ respcare.03171 
hospital stay. ${ }^{5}$ Consequently, the duration of in-patient episodes due to an exacerbation of COPD and related factors has attracted significant attention from health care providers. ${ }^{6,7}$

Despite the tremendous burden of hospital admissions, few studies have the duration of hospital stay and its association with subjects' characteristics as primary shortterm outcome parameters. ${ }^{3,7-12}$ Such knowledge could help clinicians to identify subjects who require intensive treatment, targeting therapeutic goals to encounter all the parameters that are relevant to increased stay to allow for better utilization of medical resources.

The aim of the present study was to investigate possible associations of demographic, clinical, laboratory, and functional parameters with stay of subjects admitted with a COPD exacerbation and to create a simple score for the recognition of patients who will require prolonged stay. The understanding of these influences will help optimize care for COPD patients needing hospital admission.

\section{Methods}

\section{Study Participants}

In this prospective study, we enrolled 164 consecutive COPD subjects who were admitted in 2 respiratory medicine departments of 2 tertiary hospitals (Third Respiratory Medicine Department of Sismanogleio General Hospital and the Respiratory Medicine Department of Amalia Fleming General Hospital, Athens, Greece) between January 2010 and June 2012, with a diagnosis of COPD exacerbation according to the Global Initiative for Chronic Obstructive Lung Disease (GOLD) definition. ${ }^{1}$

Inclusion criteria involved subjects with a previous diagnosis of COPD established by a respiratory physician in their records, age $\geq 40 \mathrm{y}$, current or exsmokers with smoking history $\geq 10$ pack-years, and a COPD exacerbation requiring hospital admission. Subjects with a diagnosis of another acute respiratory condition (eg, pneumonia, pneumothorax, or pulmonary embolism) or a history of respiratory disorders other than COPD (eg, asthma, bronchiectasis, or pulmonary fibrosis), subjects who were unable or unwilling to cooperate with the investigators, and subjects without spirometry data were excluded from the study. Exclusion criteria also involved COPD subjects who needed invasive or noninvasive mechanical ventilation on admission because of severe respiratory acidosis. The study protocol was approved by the local ethics committees, and all participants provided written informed consent.

\section{Study Design}

Demographic data, including gender, age, body mass index, and smoking history, were recorded on admission.

\section{QUICK LOOK}

\section{Current knowledge}

COPD is a leading cause of morbidity and mortality worldwide, resulting in a substantial economic and social burden. A COPD exacerbation is one of the most common causes of acute hospital admission, accounting for $70 \%$ of the total costs of COPD treatment.

\section{What this paper contributes to our knowledge}

The AECOPD-F score includes seven parameters at admission: Antonisen type of exacerbation, number of Exacerbations in the previous year, $\underline{\text { Charlson index of }}$ comorbidities, Oxygenation, Partial pressure of $\mathrm{P}_{\mathrm{aCO}}$ in arterial blood gases, Dyspnea according to the Borg dyspnea scale, and history of chronic respiratory Failure. These parameters were able to predict length of stay. A score $\geq 3$ was associated with prolonged hospitalization.

Exacerbation history (the number of exacerbations within the calendar year preceding the current episode), exacerbation severity according to the Anthonisen criteria, ${ }^{13}$ use of long-term oxygen therapy at home before hospitalization, and comorbid diseases were also recorded. Arterial blood gases were measured, and $\mathrm{P}_{\mathrm{aO}} / \mathrm{F}_{\mathrm{IO}_{2}}$ was calculated. The level of dyspnea was assessed using the modified Borg dyspnea scale on admission and before initiation of any treatment. ${ }^{14}$

Blood samples for complete blood count, routine biochemistry, and C-reactive protein were also collected. C-reactive protein was determined quantitatively using a particle-enhanced turbidimetric immunoassay test with the upper limit of normal value being $6 \mathrm{mg} / \mathrm{L}$ (Cobas Integra 400 for quantitative immunological determination of human C-reactive protein in serum and plasma, Roche Diagnostics, Rotkreuz, Switzerland).

Within $72 \mathrm{~h}$ of admission, all subjects underwent pulmonary function testing, including post-bronchodilation flow-volume loop, diffusing capacity for carbon monoxide, and body plethysmography evaluation of lung volumes. All tests were performed according to American Thoracic Society/European Respiratory Society guidelines. ${ }^{15-17}$

\section{Evaluation of Comorbidities}

The Charlson comorbidity index score was calculated for each subject, as this index has been shown to predict mortality. ${ }^{18}$ 


\section{Medical Treatment and Discharge}

All subjects were offered optimal medical treatment, including nebulized bronchodilators and steroids, systemic steroids, and antibiotics when needed according to the GOLD guidelines ${ }^{1}$ and Anthonisen criteria. ${ }^{13} \mathrm{O}_{2}$ was titrated according to the results of blood gas analyses.

Decisions to discharge were based on the GOLD guidelines, ${ }^{1}$ according to which a subject could leave the hospital at the time when he was able to use inhaled bronchodilators, needed inhaled therapy with short-acting $\beta$ agonists no more frequently than every $4 \mathrm{~h}$, was able to walk across the room (if previously ambulatory), was able to eat and sleep without being awakened by dyspnea, had been clinically stable for $12-24 \mathrm{~h}$, and understood completely the correct use of medications and when the subject and the physician were confident that the subject could manage successfully at home. ${ }^{1}$ All decisions for treatment and discharge were made by the attending physicians of the departments, and data on duration of stay were recorded on discharge.

\section{Statistical Analysis}

Categorical variables are presented as $n(\%)$, whereas numerical variables are presented as mean $\pm \mathrm{SD}$ or median (interquartile range [IQR]). Comparisons between groups were performed using chi-square tests for categorical data, as well as unpaired $t$ tests or Mann-Whitney $\mathrm{U}$ tests for normally distributed or skewed numerical data, respectively. We used the median stay (which in our case was 7 d) to categorize our subjects in 2 different groups, the group of normal stay (ie, stay $<$ median stay recorded in the study) and the group of prolonged stay (ie, stay $\geq$ median stay recorded in the study). All variables that had a statistically significant difference in these 2 groups were used to create receiver operating characteristic (ROC) curves for the prediction of late discharge. The cutoff value of each parameter presenting the best combination of sensitivity and specificity was used to dichotomize the variables. The variables presenting an area under the ROC curve $\geq 0.8$ were considered as possible important predictors of stay and were used in the development of a scoring system. In this scoring system, one point was given for the presence of each variable, and the total score was calculated by adding the points of each variable. This scoring system was subsequently validated in a second cohort of subjects.

Data were analyzed using SPSS 18.0 (SPSS, Chicago, Illinois), and $P$ values $<.05$ were considered statistically significant.

\section{Results}

Between February 2010 and June 2012, 164 consecutive subjects were admitted to the respiratory medicine departments of Sismanogleio General Hospital and Amalia Fleming General Hospital with a diagnosis of COPD exacerbation. The demographic and functional characteristics of the 164 subjects who were included in the study are presented in Table 1. Our subjects presented a median stay of $7 \mathrm{~d}$ (minimum stay of $2 \mathrm{~d}$ and maximum stay of $30 \mathrm{~d}$ ) and were divided in 2 groups: stay $<7 \mathrm{~d}$ (usual stay) and stay $\geq 7 \mathrm{~d}$ (prolonged stay). As shown in Table 1, the majority of demographic, functional, and laboratory characteristics of the study subjects differed between the normal-stay and prolonged-stay groups, showing that subjects who needed a prolonged stay had greater functional and biological impairment compared with the normal-stay group.

\section{Parameters Related to Hospital Stay}

The area under the curve of the ROC curves and the optimal cutoff point for each variable used to predict prolonged stay are shown in Table 2. Variables of the ROC curves for which the area under the curve was $\geq 0.8$ were considered to play an important role in the prediction of stay. This variables were the Anthonisen type of COPD exacerbation (Anthonisen type I), the number of COPD exacerbations in the previous year ( 2 or more exacerbations), the Charlson comorbidity index score (score $\geq 3$ ), $\mathrm{P}_{\mathrm{aO}_{2}} / \mathrm{F}_{\mathrm{IO}_{2}}$ on admission $(\leq 290.48 \mathrm{~mm} \mathrm{Hg}), \mathrm{P}_{\mathrm{aCO}_{2}}$ on admission ( $\geq 45 \mathrm{~mm} \mathrm{Hg}$ ), the level of dyspnea on admission according to the Borg scale ( $\geq 5$ ), and the previous history of chronic respiratory failure requiring long-term oxygen therapy.

\section{Calculation of a Simple Score for the Prediction of Stay}

To predict the difference in stay by combining the aforementioned factors, we created a score that is calculated according to the presence or absence of the aforementioned 7 factors. The method of calculating the score is provided in Table 3. This score was named AECOPD-F for the initials of the variables that are included: $\underline{A}$ for Antonisen type of exacerbation, $\underline{E}$ for number of exacerbations in the previous year, $\underline{\mathrm{C}}$ for Charlson comorbidity index score, $\underline{\mathrm{O}}$ for oxygenation on admission (according to $\left.\mathrm{P}_{\mathrm{aO}_{2}} / \mathrm{F}_{\mathrm{IO}_{2}}\right), \underline{\mathrm{P}}$ for partial pressure of $\mathrm{CO}_{2}$ in arterial blood gases on admission, $\underline{\mathrm{D}}$ for dyspnea according to the Borg dyspnea scale, and $\mathrm{F}$ for medical history of chronic respiratory failure.

The area under the curve of the score for the prediction of prolonged hospital stay is 0.960 (95\% CI 0.917-0.984), and a cutoff point of $\geq 3$ predicts prolonged stay with a 
Prediction of Hospital Stay in COPD Exacerbations

Table 1. Demographic and Functional Characteristics of the Study Subjects

\begin{tabular}{|c|c|c|c|c|}
\hline Variables & $\begin{array}{c}\text { All } \\
(n=164)\end{array}$ & $\begin{array}{c}\text { Normal Stay } \\
\text { (Hospital Stay }<7 \text { d; } \\
n=80)\end{array}$ & $\begin{array}{c}\text { Prolonged Stay } \\
\text { (Hospital Stay } \geq 7 \mathrm{~d} ; \\
n=84)\end{array}$ & $P$ \\
\hline Age (y) & $72.0(65.0-78.0)$ & $67.0(63.0-71.0)$ & $75.0(72.3-79.0)$ & $<.001^{*}$ \\
\hline Gender (males/females) & $113 / 51$ & $49 / 31$ & $64 / 20$ & $.03 *$ \\
\hline Hospital stay (d) & $7(4-10)$ & $4(3-5)$ & $10(8-13)$ & $<.001^{*}$ \\
\hline Smoking (pack-years) & $70(4-10)$ & $45(40,60)$ & $80(70-43)$ & $<.001^{*}$ \\
\hline BMI $\left(\mathrm{kg} / \mathrm{m}^{2}\right)$ & $25.6 \pm 5.4$ & $26.8 \pm 4.7$ & $24.6 \pm 5.9$ & $<.001^{*}$ \\
\hline $\mathrm{FEV}_{1} \%$ predicted & $39.6 \pm 14.2$ & $47.0 \pm 14.4$ & $33.0 \pm 11.9$ & $<.001^{*}$ \\
\hline FVC $\%$ predicted & $59.9 \pm 18.9$ & $64.8 \pm 15.9$ & $55.4 \pm 20.6$ & $<.001^{*}$ \\
\hline $\mathrm{FEV}_{1} / \mathrm{FVC}$ & $0.53 \pm 0.12$ & $0.57 \pm 0.14$ & $0.49 \pm 0.15$ & $<.001 *$ \\
\hline $\mathrm{FEF}_{25-75 \%}$ predicted & $17.1 \pm 8.5$ & $18.8 \pm 8.5$ & $15.3 \pm 8.1$ & $.006^{*}$ \\
\hline FRC $\%$ predicted & $147.9 \pm 44.9$ & $146.0 \pm 41.2$ & $150.0 \pm 48.4$ & .76 \\
\hline RV/TLC $\%$ predicted & $148.7 \pm 31.4$ & $147.9 \pm 24.6$ & $149.5 \pm 37.0$ & $.04 *$ \\
\hline $\mathrm{D}_{\mathrm{LCO}} \%$ predicted & $56.2 \pm 21.8$ & $61.0 \pm 22.5$ & $51.1 \pm 20.0$ & $.01 *$ \\
\hline Hemoglobin (g/dL) & $13.1 \pm 2.1$ & $14.2 \pm 1.6$ & $12.1 \pm 2.0$ & $<.001^{*}$ \\
\hline No. of exacerbations in previous year & $1(0-3)$ & $0(0-1)$ & $3(1-3)$ & $<.001^{*}$ \\
\hline Borg score on admission & $5(4-8)$ & $4(3-5)$ & $7(7-9)$ & $<.001^{*}$ \\
\hline $\mathrm{P}_{\mathrm{aO}_{2}} / \mathrm{F}_{\mathrm{IO}_{2}}$ on admission & $277.5 \pm 46.1$ & $301.1 \pm 44.0$ & $256.1 \pm 36.7$ & $<.001^{*}$ \\
\hline $\mathrm{P}_{\mathrm{aCO}_{2}}$ & $45.5 \pm 9.2$ & $40.2 \pm 4.3$ & $50.5 \pm 9.8$ & $<.001^{*}$ \\
\hline C-reactive protein on admission $(\mathrm{mg} / \mathrm{L})$ & $7.7(2.3-15.0)$ & $4(1.5-7.8)$ & $20.0(5.8-19.5)$ & $<.001^{*}$ \\
\hline White blood cells & $12,255(9,445-16,500)$ & $11,000(8,900-14,115)$ & $13,100(10,550-18,500)$ & $<.001^{*}$ \\
\hline Anthonisen-type I/II/III exacerbations & $87 / 22 / 55$ & $15 / 14 / 51$ & $72 / 8 / 4$ & $<.001^{*}$ \\
\hline Long-term oxygen therapy (\%) & $81.0(49.4 \%)$ & $12.0(15.0 \%)$ & $69.0(82.1 \%)$ & $<.001^{*}$ \\
\hline Charlson comorbidity index score & $1(1-3)$ & $1(0-1)$ & $3(3-4)$ & $<.001^{*}$ \\
\hline $\begin{array}{l}\text { Values are expressed as mean } \pm \mathrm{SD} \text { or median (inter } \\
* \text { Statistically significant difference between normal-s } \\
\mathrm{BMI}^{\mathrm{B}}=\text { body mass index } \\
\mathrm{FEF}_{25-75 \%}=\text { forced expiratory flow between } 25 \% \text { and } \\
\mathrm{FRC}=\text { functional residual capacity } \\
\mathrm{RV} / \mathrm{TLC}=\text { residual volume/total lung capacity } \\
\mathrm{D}_{\mathrm{LCO}}=\text { diffusing lung capacity for carbon monoxide }\end{array}$ & $\begin{array}{l}\text { ange). } \\
\text { d) and prolonged-stay ( } \geq 7 \text { d) g } \\
\text { VC }\end{array}$ & & & \\
\hline
\end{tabular}

sensitivity of $84.5 \%$ and a specificity of $92.5 \%$. The ROC curve of the AECOPD-F score is provided in Figure 1. The difference between subjects with a score $<3$ and those with a score $\geq 3$ regarding hospital days is shown in Figure 2 and was 4 (IQR 3-5) versus 9 (IQR 7-13), respectively $(P<.001)$.

In the following months, we evaluated this score in an additional group of 88 consecutive subjects with COPD exacerbation admitted in our department. The subjects' demographic characteristics are shown in Table 4. These additional subjects were also divided in 2 groups according to the AECOPD-F score ( $\geq 3$ and $<3$ ), and stay was recorded. We observed that subjects with a score $\geq 3$ on admission required prolonged stay compared with subjects with a score $<3(8.0$ [IQR 6.0-10.0] vs 6.5 [IQR 4.0-9.0] d, respectively, $P=.007$ ) (Fig. 3).

\section{Discussion}

In this study, we found that a simple clinical score (which includes 7 parameters that can be easily obtained on ad- mission for a COPD exacerbation) can identify subjects at risk for prolonged hospitalization. People hospitalized for COPD exacerbations have a subsequent increased risk of death, ${ }^{3,8}$ suggesting the importance of factors affecting the duration of hospital stay.

Previous studies have reported a variety of factors that determine stay following a COPD exacerbation. ${ }^{7-11}$ Factors associated with longer stay include increased dyspnea, ${ }^{7}$ high breathing frequency, high $\mathrm{P}_{\mathrm{aCO}},{ }^{19,20}$ comorbidities, advanced age, poor performance status, low $\mathrm{FEV}_{1},{ }^{21}$ and cause of exacerbations (exacerbations due to infective causes were associated with longer stay). ${ }^{8}$ Furthermore, socioeconomic deprivation ${ }^{22}$ and comorbid depressive symptoms ${ }^{23,24}$ in subjects with COPD have been also related to longer hospital stay. In our study, several demographic, clinical, and laboratory parameters possibly related to stay were investigated. Although almost all of them differed significantly between the 2 groups of subjects (normal-stay and prolonged-stay groups), only $7 \mathrm{pa}-$ rameters were finally found to be significant in the ROC analysis and were included in the prediction score. 
Prediction of Hospital Stay in COPD Exacerbations

Table 2. Random Prediction of Outcome Curves of Predictors of Late Hospital Discharge

\begin{tabular}{|c|c|c|c|c|c|}
\hline & Area Under the Curve & Best Cutoff Value & $\begin{array}{c}\text { Sensitivity } \\
(\%)\end{array}$ & $\begin{array}{l}\text { Specificity } \\
(\%)\end{array}$ & $95 \% \mathrm{CI}$ \\
\hline Age (y) & 0.791 & $\geq 72$ & 84.5 & 76.2 & $0.721-0.851$ \\
\hline Gender (males/females) & 0.575 & Male & 76.2 & 38.7 & $0.495-0.651$ \\
\hline Smoking (pack-years) & 0.792 & $\geq 61$ & 79.8 & 75.9 & $0.722-0.852$ \\
\hline BMI $\left(\mathrm{kg} / \mathrm{m}^{2}\right)$ & 0.685 & $\leq 21.7$ & 58.5 & 93.6 & $0.607-0.756$ \\
\hline $\mathrm{FEV}_{1} \%$ predicted & 0.763 & $\leq 38$ & 82.9 & 65.4 & $0.689-0.827$ \\
\hline FVC $\%$ predicted & 0.673 & $\leq 51$ & 59.8 & 79.5 & $0.594-0.745$ \\
\hline $\mathrm{FEV}_{1} / \mathrm{FVC}$ & 0.667 & $\leq 50$ & 64.6 & 69.2 & $0.588-0.739$ \\
\hline $\mathrm{FEF}_{25-75 \%}$ predicted & 0.632 & $\leq 15$ & 67.1 & 65.4 & $0.549-0.710$ \\
\hline RV/TLC $\%$ predicted & 0.598 & $\geq 144$ & 69.2 & 52.0 & $0.516-0.677$ \\
\hline $\mathrm{D}_{\text {LCO }} \%$ predicted & 0.623 & $\leq 46$ & 52.2 & 71.1 & $0.539-0.702$ \\
\hline Hemoglobin (g/dL) & 0.775 & $\leq 12.4$ & 63.0 & 91.8 & $0.700-0.838$ \\
\hline No. of exacerbations in previous year & $0.841^{*}$ & $\geq 2$ & 67.4 & 92.5 & $0.776-0.893$ \\
\hline Borg score on admission & $0.914^{*}$ & $\geq 5$ & 83.3 & 91.1 & $0.860-0.952$ \\
\hline $\mathrm{P}_{\mathrm{aO}_{2}} / \mathrm{F}_{\mathrm{IO}_{2}}$ on admission & $0.828^{*}$ & $\leq 290.48$ & 89.0 & 75.7 & $0.760-0.884$ \\
\hline $\mathrm{P}_{\mathrm{aCO}_{2}}$ & $0.841^{*}$ & $\geq 45$ & 76.8 & 89.2 & $0.774-0.895$ \\
\hline C-reactive protein on admission (mg/L) & 0.727 & $\geq 10$ & 69.5 & 83.1 & $0.651-0.795$ \\
\hline Anthonisen-type exacerbation & $0.861^{*}$ & Type I & 85.7 & 81.2 & $0.798-0.910$ \\
\hline Long-term oxygen therapy $(\%)$ & $0.836^{*}$ & Yes & 82.1 & 85.0 & $0.770-0.889$ \\
\hline Charlson comorbidity index score & $0.831 *$ & $\geq 3$ & 76.2 & 95.0 & $0.764-0.885$ \\
\hline \multicolumn{6}{|c|}{ 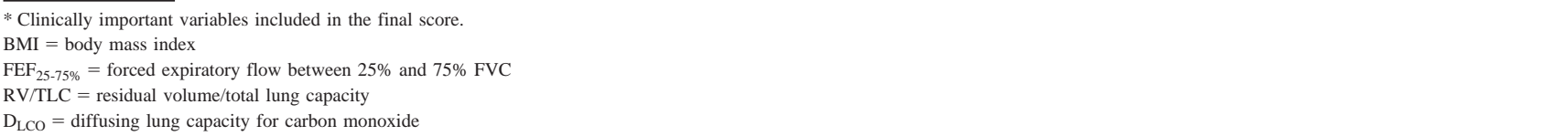 } \\
\hline
\end{tabular}

Table 3. Calculation of the AECOPD-F Score for Prediction of Stay

\begin{tabular}{lcc}
\hline \hline \multicolumn{1}{c}{ Variable } & 0 & 1 \\
\hline A: Anthonisen type of exacerbation & II or III & I \\
E: No. of Exacerbations in the previous year & $<2$ & $\geq 2$ \\
C: Charlson comorbidity index score & $<3$ & $\geq 3$ \\
O: Oxygenation on admission (mm Hg) & $>290$ & $\leq 290$ \\
P: Partial pressure of $\mathrm{P}_{\mathrm{aCO}_{2}}$ in arterial blood & $<45$ & $\geq 45$ \\
$\quad$ gases (mm Hg) & & \\
D: Borg Dyspnea score on admission & $<5$ & $\geq 5$ \\
F: History of chronic respiratory Failure & No & Yes \\
\hline
\end{tabular}

Data on the impact of age on stay in subjects hospitalized for a COPD exacerbation are controversial. Although there is evidence that age is an independent predictor of stay, $8,21,25$ for subjects older than 80 y requiring longer hospitalizations compared with those $40-59$ y old, ${ }^{8}$ it has been suggested that stay time was probably affected by the presence of multiple comorbidities, living alone, and the use of respiratory depressant drugs rather than age. ${ }^{26}$ In agreement with the aforementioned study, age was not a predictor of late discharge in our group of subjects.

Anthonisen-type I/II exacerbation was an independent predictor of late recovery in out-patients with COPD exacerbation. ${ }^{10}$ To our knowledge, there are no relevant data about the impact of Anthonisen-type exacerbation in hos-

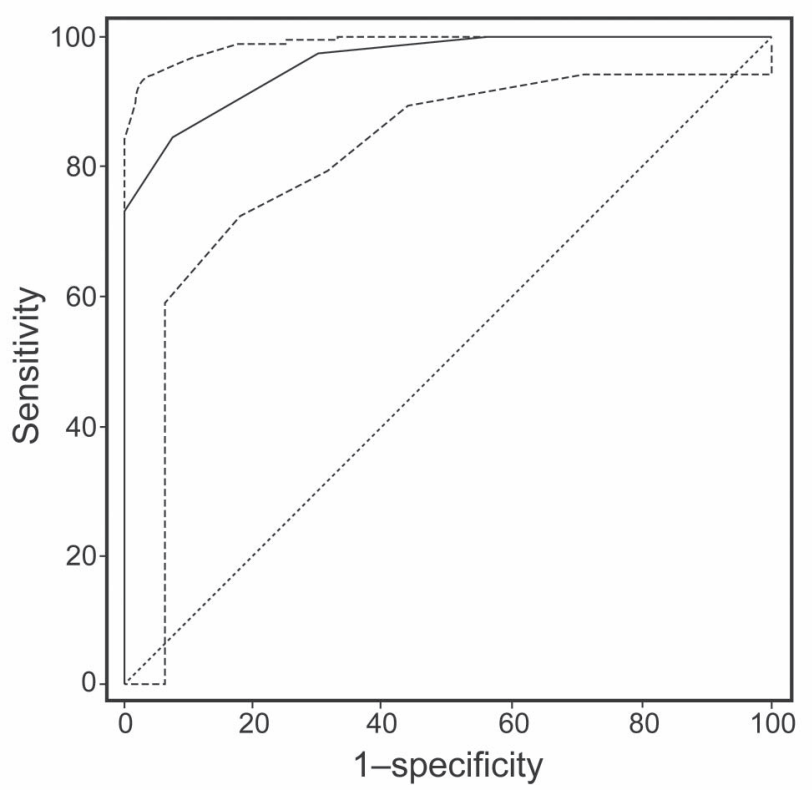

Fig. 1. Receiver operating characteristic curve of the AECOPD-F score. Area under the curve: 0.960; standard error: 0.016; $95 \% \mathrm{Cl}$ $0.917-0.984 ; P<.001$. A cutoff point $\geq 3$ predicts prolonged stay with a sensitivity of $84.5 \%$ and a specificity of $92.5 \%$.

pitalized COPD subjects. Our data showed that Anthonisentype I exacerbation was a strong predictor of stay. 


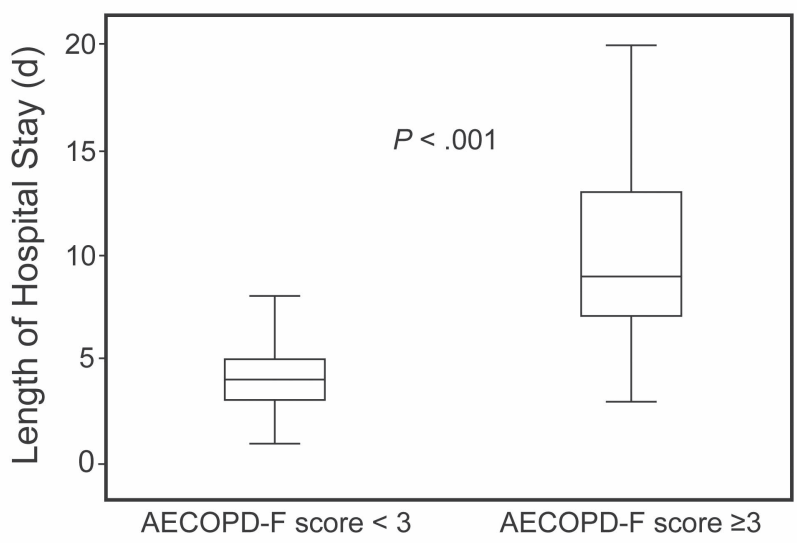

Fig. 2. Hospital stay for subjects with an AECOPD-F score of $<3$ and those with a score of $\geq 3$ in the original study cohort. Whiskers refer to the minimum and maximum values. Box lines represent the lower and upper quartiles. The line in the box represents the median value.

The most accurate method to identify the frequent exacerbators in clinical practice is examination of previous exacerbation history. In a study of a large cohort of outpatients with COPD exacerbation, ${ }^{10}$ history of frequent exacerbations was one of the main factors associated with late recovery ( $\geq 8 \mathrm{~d}$ ). There are no studies examining the influence of previous hospitalizations due to a COPD exacerbation on stay. According to our data, 2 or more exacerbations in the year before current admission could predict prolonged stay.

Comorbidities are among the most frequently identified prognostic factors of in-hospital outcome ${ }^{27}$ and were independent predictors of stay in previous studies. ${ }^{8,9,20,28,29}$

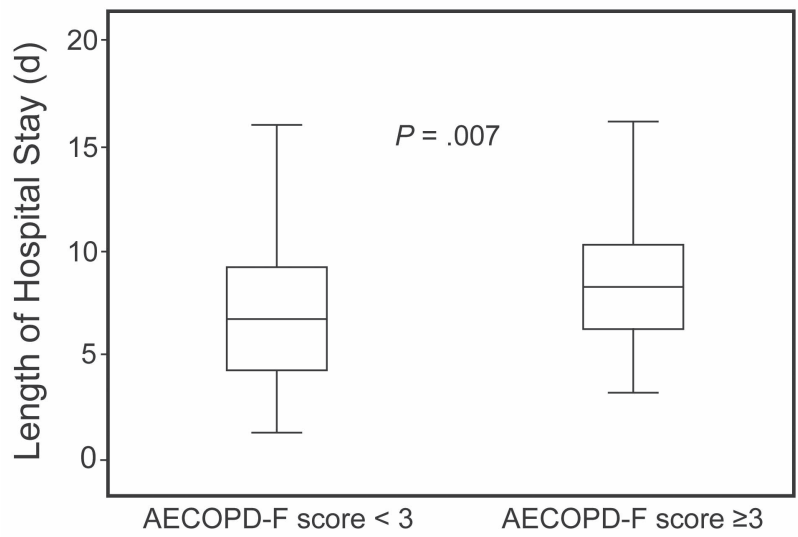

Fig. 3. Hospital stay for subjects with an AECOPD-F score of $<3$ and those with a score of $\geq 3$ in the validation group. Whiskers refer to the minimum and maximum values. Box lines represent the lower and upper quartiles. The line in the box represents the median value.

It is reasonable to expect stay to be longer in subjects with multiple underlying health conditions. A Charlson comorbidity index score $\geq 3$ in our study identified subjects with prolonged stay.

Low $\mathrm{P}_{\mathrm{aO}} / \mathrm{F}_{\mathrm{IO}_{2}}{ }^{30}$ and preadmission long-term oxygen therapy ${ }^{11}$ independently predict 6 -month mortality and high readmission rates. However, none of these parameters have been studied in relation to stay. These indices probably reflect the severity of both the acute illness and the underlying condition; thus, we hypothesized that they could also predict the duration of hospital stay. Our data confirmed that $\mathrm{P}_{\mathrm{aO}_{2}} / \mathrm{F}_{\mathrm{IO}_{2}} \leq 290 \mathrm{~mm} \mathrm{Hg}$ on admission could predict prolonged stay. Chronic respiratory failure with

Table 4. Demographic Characteristics of the 88 Subjects Used for the Evaluation of the AECOPD-F Score

\begin{tabular}{|c|c|c|c|c|}
\hline Variable & All $(n=88)$ & $\begin{array}{c}\text { AECOPD-F score }<3 \\
(n=32)\end{array}$ & $\begin{array}{c}\text { AECOPD-F score } \geq 3 \\
(n=56)\end{array}$ & $P$ \\
\hline Age (y) & $72.0(65.0-75.0)$ & $71.5(64.0-75.7)$ & $72.0(66.0-74.8)$ & .94 \\
\hline Gender (males/females), $n$ & $68 / 20$ & $23 / 9$ & $45 / 11$ & .26 \\
\hline Smoking (pack-years) & $70(60-100)$ & $80(60-100)$ & $70(52.5-100)$ & .67 \\
\hline BMI $\left(\mathrm{kg} / \mathrm{m}^{2}\right)$ & $28.2(25.9-32.4)$ & $26.9(25.4-30.0)$ & $24.4(26.0-33.7)$ & $.04 *$ \\
\hline $\mathrm{FEV}_{1} \%$ predicted & $37.0(27.0-48.9)$ & $42.9(31.0-52.7)$ & $33.0(23.9-47.8)$ & .08 \\
\hline No. of exacerbations in previous year & $1.0(0.0-2.0)$ & $1.0(0.0-1.7)$ & $1.0(0.0-2.0)$ & .79 \\
\hline Charlson comorbidity index score & $2.0(1.0-2.0)$ & $1.0(1.0-2.0)$ & $2.0(1.0-3.0)$ & .50 \\
\hline Borg score on admission & $6.0(5.0-8.0)$ & $5.0(4.0-7.0)$ & $7.0(5.0-8.7)$ & $.002 *$ \\
\hline Anthonisen-type exacerbation, $n$ & $49 / 19 / 20$ & $15 / 3 / 14$ & $34 / 16 / 6$ & $.004 *$ \\
\hline $\mathrm{P}_{\mathrm{aO}_{2}} / \mathrm{F}_{\mathrm{IO}_{2}}$ on admission & $238(189-295)$ & $305(271-319)$ & $204(173-249)$ & $<.001^{*}$ \\
\hline $\mathrm{P}_{\mathrm{aCO}_{2}}$ & $44(37-55)$ & $38(35-42)$ & $50(39-62)$ & $<.001^{*}$ \\
\hline Prior chronic respiratory failure, $n(\%)$ & $28(31.8)$ & $4(12.5)$ & $24(42.8)$ & $<.001^{*}$ \\
\hline Hospital stay (d) & $8.0(5.2-10.0)$ & $6.5(4.0-9.0)$ & $8.0(6.0-10.0)$ & $.007 *$ \\
\hline
\end{tabular}




\section{Prediction of Hospital Stay in COPD Exacerbations}

long-term oxygen therapy could also predict increased hospital stay. In previous studies, ${ }^{19,20}$ high $\mathrm{P}_{\mathrm{aCO}_{2}}$ levels were associated with the need for longer hospital stay. Our results are in concordance with these previous data showing that $\mathrm{P}_{\mathrm{aCO}_{2}} \geq 45 \mathrm{~mm} \mathrm{Hg}$ on admission was correlated with longer stay.

Increased breathlessness is the principal symptom of a COPD exacerbation. There is only one study evaluating the impact of dyspnea on stay. ${ }^{7}$ However, in the aforementioned study, dyspnea was measured according to the Medical Research Council scale. We believe that the modified Borg scale is more accurate in reflecting progressive breathlessness occurring during the time course of a COPD exacerbation. The modified Borg dyspnea scale consists of 10 statements with small differences in perception of symptoms from level to level, whereas the Medical Research Council scale comprises a 5-statement scale with larger differences in perceived symptoms between levels. Moreover, the Medical Research Council scale represents more of an exercise tolerance than a dyspnea assessment tool. In our study, a Borg score on admission of $\geq 5$ was the strongest predictor of stay, and this further supports the central role of dyspnea in the evaluation of subjects on admission for a COPD exacerbation.

We noted certain limitations of our study. First, subjects with severe respiratory acidosis $(\mathrm{pH}<7.30)$ who were candidates for noninvasive mechanical ventilation were not included in the study. It would be useful for our score to be applied to subjects with COPD exacerbation who need noninvasive mechanical ventilation, as it seems possible that it could also be capable of predicting stay in this group of subjects. Second, data about important covariates that previous studies have shown to determine stay (eg, socioeconomic status or anxiety and depression) were not evaluated in this study. Finally, in our study, the number of female subjects was lower compared with that of male subjects, and the AECOPD-F score has not been validated separately in male and female subjects. The difference in the number of male and female subjects probably reflects the different incidence of COPD between genders in our Greek population. ${ }^{31}$ Despite the above limitations, our study described a simple prediction score of hospitalization duration in subjects with COPD exacerbations, and this score was further validated in a second cohort of subjects from our hospital. Our data could be applied to subjects managed by assisted discharge schemes, which many countries now use. Although many studies have shown that the supported discharge programs allow a significant reduction in stay of subjects hospitalized for COPD and reduce the utilization of hospital resources without increasing the risk of hospital readmissions, subjects' inclusion criteria for early discharge were not clearly defined. ${ }^{32-35}$ The AECOPD-F score could be used to identify subjects who could be discharged earlier and those who may need more prolonged hospitalization and/or extended support at home. The implementation of this score in the planning of the management of such subjects could be evaluated in a future study.

\section{Conclusions}

Our study detected predictors of stay from a large number of evaluated parameters and provided a simple clinical score implementing 7 parameters easily obtained on subject admission. The AECOPD-F score can accurately predict prolonged hospitalization for a COPD exacerbation, and the implementation of this score in clinical practice could be very useful in the discharge planning of such subjects. Given the substantial economic consequences of stay on hospital costs, this result could help improve the management of individual COPD subjects and contribute to the optimization of health care resource utilization.

\section{REFERENCES}

1. Global Initiative for Chronic Obstructive Lung Disease. Global strategy for the diagnosis, management, and prevention of chronic obstructive pulmonary disease. Updated 2014. http://www.goldcopd. org/uploads/users/files/GOLD_Report2014_Feb07.pdf. Accessed May 14, 2014.

2. Ornek T, Tor M, Altýn R, Atalay F, Geredeli E, Soylu O, Erboy F. Clinical factors affecting the direct cost of patients hospitalized with acute exacerbation of chronic obstructive pulmonary disease. Int J Med Sci 2012;9(4):285-290.

3. Connors AF Jr, Dawson NV, Thomas C, Harrell FE Jr, Desbiens N, Fulkerson WJ, et al. Outcomes following acute exacerbation of severe chronic obstructive lung disease; the SUPPORT investigators (Study to Understand Prognoses and Preferences for Outcomes and Risks of Treatments). Am J Respir Crit Care Med 1996;154(4 Pt 1):959-967.

4. Strassels SA, Smith DH, Sullivan SD, Mahajan PS. The costs of treating COPD in the United States. Chest 2001;119(2):344-352.

5. Sullivan SD, Ramsey SD, Lee TA. The economic burden of COPD. Chest 2000;117(2 Suppl):5S-9S.

6. Steer J, Gibson GJ, Bourke SC. Predicting outcomes following hospitalization for acute exacerbations of COPD. QJM 2010;103(11): 817-829.

7. Tsimogianni AM, Papiris SA, Stathopoulos GT, Manali ED, Roussos C, Kotanidou A. Predictors of outcome after exacerbation of chronic obstructive pulmonary disease. J Gen Intern Med 2009;24(9): 1043-1048.

8. Agboado G, Peters J, Donkin L. Factors influencing the length of hospital stay among patients resident in Blackpool admitted with COPD: a cross-sectional study. BMJ Open 2012;2(5):e000869.

9. Almagro P, Cabrera FJ, Diez J, Boixeda R, Alonso Ortiz MB, Murio $\mathrm{C}$, et al. Comorbidities and short-term prognosis in patients hospitalized for acute exacerbation of COPD: the ESMI study. Chest 2012;142(5):1126-1133.

10. Anzueto A, Miravitlles M, Ewig S, Legnani D, Heldner S, Stauch K. Identifying patients at risk of late recovery ( $\geq 8$ days) from acute exacerbation of chronic bronchitis and COPD. Respir Med 2012; 106(9):1258-1267.

11. Bahadori K, FitzGerald JM, Levy RD, Fera T, Swiston J. Risk factors and outcomes associated with chronic obstructive pulmonary disease exacerbations requiring hospitalization. Can Respir J 2009; 16(4):e43-e49. 


\section{Prediction of Hospital Stay in COPD Exacerbations}

12. Almagro P, Cabrera FJ, Diez J, Boixeda R, Alonso Ortiz MB, Murio $\mathrm{C}$, et al. Comorbidities and short-term prognosis in patients hospitalized for acute exacerbation of COPD: the EPOC en Servicios de medicina interna (ESMI) study. Chest 2012;142(5):1126-1133.

13. Anthonisen NR, Manfreda J, Warren CP, Hershfield ES, Harding GK, Nelson NA. Antibiotic therapy in exacerbations of chronic obstructive pulmonary disease. Ann Intern Med 1987;106(2):196-204.

14. Borg GA. Psychophysical bases of perceived exertion. Med Sci Sports Exerc 1982;14(5):377-381.

15. Standardization of Spirometry, 1994 Update. American Thoracic Society. Am J Respir Crit Care Med 1995;152(3):1107-1136.

16. Wanger J, Clausen JL, Coates A, Pedersen OF, Brusasco V, Burgos F, et al. Standardisation of the measurement of lung volumes. Eur Respir J 2005;26(3):511-522.

17. Macintyre N, Crapo RO, Viegi G, Johnson DC, van der Grinten CP, Brusasco V, et al. Standardisation of the single-breath determination of carbon monoxide uptake in the lung. Eur Respir J 2005;26(4): 720-735.

18. Charlson ME, Pompei P, Ales KL, MacKenzie CR. A new method of classifying prognostic comorbidity in longitudinal studies: development and validation. J Chronic Dis 1987;40(5):373-383.

19. Mushlin AI, Black ER, Connolly CA, Buonaccorso KM, Eberly SW. The necessary length of hospital stay for chronic pulmonary disease. JAMA 1991;266(1):80-83.

20. Villalta J, Sequeira E, Cereijo AC, Siso A, de la Sierra A. [Factors predicting a short length of stay for acute exacerbations of chronic obstructive pulmonary disease.] Med Clin 2005;124(17):648-650. Article in Spanish.

21. Roberts CM, Lowe D, Bucknall CE, Ryland I, Kelly Y, Pearson MG. Clinical audit indicators of outcome following admission to hospital with acute exacerbation of chronic obstructive pulmonary disease. Thorax 2002;57(2):137-141.

22. Wong AW, Gan WQ, Burns J, Sin DD, van Eeden SF. Acute exacerbation of chronic obstructive pulmonary disease: influence of social factors in determining length of hospital stay and readmission rates. Can Respir J 2008;15(7):361-364.

23. Papaioannou AI, Bartziokas K, Tsikrika S, Karakontaki F, Kastanakis E, Banya W, et al. The impact of depressive symptoms on recovery and outcome of hospitalised COPD exacerbations. Eur Respir J 2013;41(4):815-823.

24. Ng TP, Niti M, Tan WC, Cao Z, Ong KC, Eng P. Depressive symptoms and chronic obstructive pulmonary disease: effect on mortality, hospital readmission, symptom burden, functional status, and quality of life. Arch Intern Med 2007;167(1):60-67.

25. Connolly MJ, Lowe D, Anstey K, Hosker HS, Pearson MG, Roberts CM. Admissions to hospital with exacerbations of chronic obstructive pulmonary disease: effect of age related factors and service organisation. Thorax 2006;61(10):843-848.

26. Incalzi RA, Pedone C, Onder G, Pahor M, Carbonin PU, GIFA. Gruppo Italiano di Farmacovigilanza (Italian Group for Pharmacological Survey in the Elderly). Predicting length of stay of older patients with exacerbated chronic obstructive pulmonary disease. Aging 2001;13(1):49-57.

27. Roche N, Rabbat A, Zureik M, Huchon G. Chronic obstructive pulmonary disease exacerbations in emergency departments: predictors of outcome. Curr Opin Pulm Med 2010;16(2):112-117.

28. de la Iglesia F, Valiño P, Pita S, Ramos V, Pellicer C, Nicolás R, Diz-Lois F. Factors predicting a hospital stay of over 3 days in patients with acute exacerbation of chronic obstructive pulmonary disease. J Intern Med 2002;251(6):500-507.

29. Kinnunen T, Säynäjäkangas O, Tuuponen T, Keistinen T. Impact of comorbidities on the duration of COPD patients' hospital episodes. Respir Med 2003;97(2):143-146.

30. Roche N, Zureik M, Soussan D, Neukirch F, Perrotin D. Predictors of outcomes in COPD exacerbation cases presenting to the emergency department. Eur Respir J 2008;32(4):953-961.

31. Tzanakis N, Anagnostopoulou U, Filaditaki V, Christaki P, Siafakas N. Prevalence of COPD in Greece. Chest 2004;125(3):892-900.

32. Cotton MM, Bucknall CE, Dagg KD, Johnson MK, MacGregor G, Stewart C, Stevenson RD. Early discharge for patients with exacerbations of chronic obstructive pulmonary disease: a randomized controlled trial. Thorax 2000;55(11):902-906.

33. Davies L, Wilkinson M, Bonner S, Calverley PM, Angus RM. "Hospital at home" versus hospital care in patients with exacerbations of chronic obstructive pulmonary disease: prospective randomised controlled trial. BMJ 2000;321(7271):1265-1268.

34. Sala E, Alegre L, Carrera M, Ibars M, Orriols FJ, Blanco ML, et al. Supported discharge shortens hospital stay in patients hospitalized because of an exacerbation of COPD. Eur Respir J 2001;17(6):11381142.

35. Utens CM, Goossens LM, Smeenk FW, Rutten-van Molken MP, van Vliet M, Braken MW, et al. Early assisted discharge with generic community nursing for chronic obstructive pulmonary disease exacerbations: results of a randomised controlled trial. BMJ Open 2012; 2(5):e001684 